\title{
Diabetic and idiopathic gastroparesis is associated with loss of CD206-positive macrophages in the gastric antrum
}

\author{
M. Grover ${ }^{1}$ | C. E. Bernard ${ }^{1}$ \\ P. J. Pasricha ${ }^{2}$ \\ J. Tonascia ${ }^{4}$ \\ K. L. Koch ${ }^{5}$ । \\ R. W. McCallum ${ }^{6}$ \\ L. A. B. Nguyen ${ }^{8}$ \\ T. L. Abell ${ }^{9}$ \\ W. J. Snape ${ }^{10}$ \\ T. J. McKenzie ${ }^{1}$ \\ F. A. Hamilton ${ }^{11}$ \\ G. Farrugia ${ }^{1}$

\section{Consortium (GpCRC)}

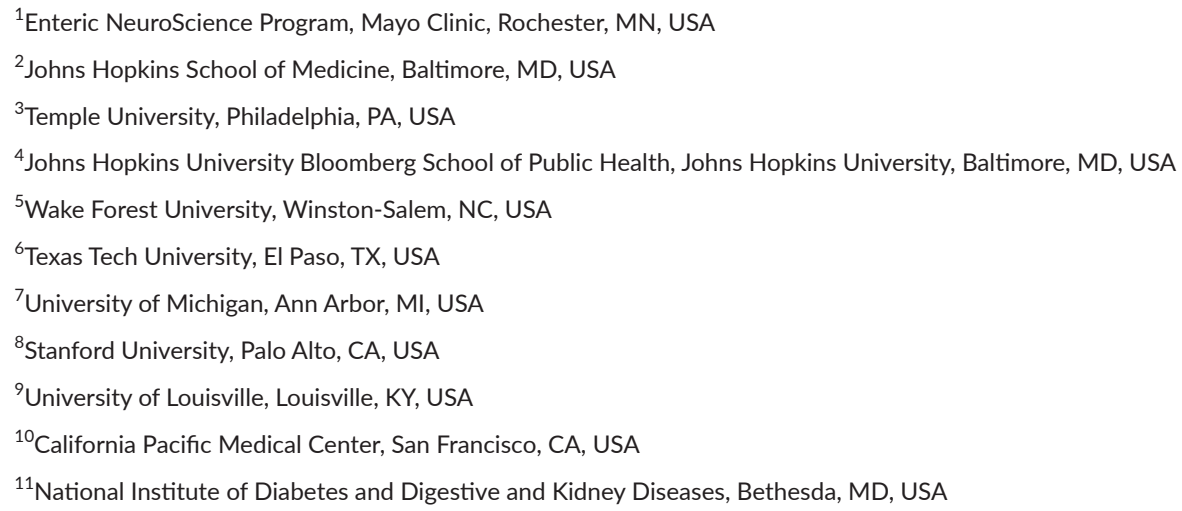

H. P. Parkman ${ }^{3}$ ।

S. J. Gibbons ${ }^{1}$

I. Sarosiek ${ }^{6}$ | W. L. Hasler ${ }^{7}$ |

M. L. Kendrick ${ }^{1}$ | T. A. Kellogg ${ }^{1}$ |

NIDDK Gastroparesis Clinical Research

\section{Correspondence}

Madhusudan Grover, M.D. and Gianrico Farrugia, M.D.

Division of Gastroenterology \& Hepatology

Enteric NeuroScience Program

Mayo Clinic

Rochester, MN, USA.

Emails: grover.madhusudan@mayo.edu and

farrugia.gianrico@mayo.edu

Funding information

National Institute of Diabetes and Digestive and Kidney Diseases, Grant/Award

Number: U01DK073983, U01DK073975, U01DK073985, U01DK074007, U01DK073974 and U01DK074008; K23,

Grant/Award Number: DK103911

\begin{abstract}
Background: Animal studies have increasingly highlighted the role of macrophages in the development of delayed gastric emptying. However, their role in the pathophysiology of human gastroparesis is unclear. Our aim was to determine changes in macrophages and other cell types in the gastric antrum muscularis propria of patients with diabetic and idiopathic gastroparesis.

Methods: Full thickness gastric antrum biopsies were obtained from patients enrolled in the Gastroparesis Clinical Research Consortium (11 diabetic, 6 idiopathic) and 5 controls. Immunolabeling and quantitative assessment was done for interstitial cells of Cajal (ICC) (Kit), enteric nerves protein gene product 9.5, neuronal nitric oxide synthase, vasoactive intestinal peptide, substance $P$, tyrosine hydroxylase), overall immune cells (CD45) and antiinflammatory macrophages (CD206). Gastric emptying was assessed using nuclear medicine scintigraphy and symptom severity using the Gastroparesis Cardinal Symptom Index. Results: Both diabetic and idiopathic gastroparesis patients showed loss of ICC as compared to controls (Mean [standard error of mean]/hpf: diabetic, 2.28 [0.16]; idiopathic, 2.53 [0.47]; controls, 6.05 [0.62]; $P=.004$ ). Overall immune cell population (CD45) was unchanged but there was a loss of anti-inflammatory macrophages
\end{abstract}


(CD206) in circular muscle (diabetic, 3.87 [0.32]; idiopathic, 4.16 [0.52]; controls, 6.59 [1.09]; $P=.04$ ) and myenteric plexus (diabetic, 3.83 [0.27]; idiopathic, 3.59 [0.68]; controls, 7.46 [0.51]; $P=.004)$. There was correlation between the number of ICC and CD206-positive cells ( $r=.55, P=.008)$. Enteric nerves (PGP9.5) were unchanged: diabetic, 33.64 (3.45); idiopathic, 41.26 (6.40); controls, 46.80 (6.04).

Conclusion: Loss of antral CD206-positive anti-inflammatory macrophages is a key feature in human gastroparesis and it is associates with ICC loss.

KEYWORDS

enteric nervous system, gastrointestinal motility, immune cells, interstitial cells of Cajal, macrophages

\section{1 | INTRODUCTION}

Human diabetic and idiopathic gastroparesis and animal models of delayed gastric emptying are characterized by the loss of interstitial cells of Cajal (ICC) as a key cellular abnormality. Previous studies from the NIH Gastroparesis Clinical Research Consortium (GpCRC) have shown a $50 \%$ loss of ICC in gastric body muscularis and ultrastructural damage in remaining ICC in the majority of patients with gastroparesis. ${ }^{1,2}$ Other studies also report significant or complete absence of ICC networks. ${ }^{3,4}$ The loss of ICC immunoreactivity (ir) correlated with diabetes severity. ${ }^{5}$ Additional cellular abnormalities include loss or damage of nerves or neurons in a subset of patients raising the possibility of a common underlying mechanism of damage to the cell types that regulate gastrointestinal motility. ${ }^{1,2,4}$ More recently, macrophages have been shown to be critical in the pathophysiology of gastroparesis in animal models. In the non-obese diabetic (NOD) mouse model, development of diabetes was associated with appearance of anti-inflammatory (M2 or alternatively activated, CD206 ir) macrophages. However, gastric emptying delay was evident only after M2 macrophages phenotypically switched to pro-inflammatory (M1 or classically activated) macrophages ${ }^{6}$ and ICC were lost. In another study using diabetic, macrophage-deficient CSF1 ${ }^{\mathrm{op} / \mathrm{op}}$ mice, absence of muscle layer macrophages was protective against the development of delayed gastric emptying. ${ }^{7}$ These data suggest that interactions between the innate immune system, specifically macrophages, and ICC and the neuromuscular apparatus may be central in the pathophysiology of human gastroparesis. ${ }^{8}$

In our previous study, we provided evidence supporting the existence of this paradigm in the gastric body of patients with diabetic gastroparesis where loss of ICC correlated with the number of M2 macrophages. ${ }^{9}$ It was not apparent that the observed changes could be found in other regions of the stomach that are also important for gastric motility such as the antrum. Coordinated activity in the antrum is required for grinding of food particles and passage of food into the duodenum. Postprandial antral hypomotility was observed in over $60 \%$ of patients with gastroparesis, and was associated with a significantly lower motility index in patients with autonomic neuropathy. ${ }^{10}$ Duplex sonography showed decreased frequency of coordinated antroduodenal contractions and reduced anterograde transpyloric flow in gastroparetic patients with autonomic neuropathy. ${ }^{11}$ Gastroparesis patients had a reduced number of antral waves $\geq 6 \mathrm{~cm}$ in duration which correlated with gastric emptying and improved in response to cisapride, a prokinetic agent. ${ }^{12}$ In animal models, ICC are more affected in the antrum than the body ${ }^{13,14}$ and gastric antral ICC and stem cell factor expression were found to be reduced in streptozocin-induced diabetic mice. ${ }^{15}$ Reduced ICC numbers, structural ICC degeneration, and reduced enteric nerves limited to gastric antrum was associated with delayed gastric emptying in this model. ${ }^{16}$

The cellular changes in gastric antrum in human gastroparesis are not well known. Therefore, the aim of this study was to determine: (i) if CD206-positive macrophages shown to protect against cellular damage in animal models of gastroparesis are also decreased in the antrum of humans with gastroparesis, (ii) whether there are changes in other cell types known to be important for gastric motility and (iii) the relationship of these cellular findings with clinical symptoms of gastroparesis.

\section{2 | METHODS}

\section{1 | Specimens}

Full thickness gastric antrum biopsies were obtained from 11 diabetic, six idiopathic gastroparesis patients undergoing implantation of a gastric electrical stimulator, and from five controls without diabetes or gastroparesis undergoing obesity surgery. All patients were $>18$ years of age with symptoms of at least 12-week duration, delayed gastric emptying on scintigraphy ( $>60 \%$ retention at 2 hours or $>10 \%$ retention at 4 hours), and no evidence of obstruction. Exclusion criteria included presence of active inflammatory bowel disease, eosinophilic gastroenteritis, neurological conditions, acute liver or renal failure, and history of total or subtotal gastric resection. Tissue collection was done in standardized fashion with established protocols by the participating sites of the GpCRC and tissue was shipped to the histology core at Mayo Clinic. Tissue was fixed in 4\% paraformaldehyde and cryopreserved until further use. All gastroparesis patients provided informed consent for procurement and use of gastric tissue at the clinical sites of GpCRC. All control tissues were obtained in a de-identified fashion with patient consent at Mayo Clinic in an IRB-approved protocol. 


\section{2 | Light microscopy}

Twelve micrometer sections were cut for $\mathrm{H} \& \mathrm{E}$, trichrome to assess fibrosis, and immunofluorescence for enteric nervous system (ENS), ICC, and immune cell markers. Protein gene product 9.5 (PGP9.5) was used as general marker for nerves, neuronal nitric oxide synthase (nNOS), vasoactive intestinal peptide (VIP) for the inhibitory component, and substance $\mathrm{P}$ for the excitatory component of the ENS. Tyrosine hydroxylase ( $\mathrm{TH}$ ) was used to assess extrinsic sympathetic innervation, Kit to assess ICC, CD45 to assess overall immune cells, and CD206 to assess M2 (alternatively activated) macrophages. Details on antibodies are provided in Table S1.

\section{3 | Quantification}

All quantitative assessment was done in a blinded fashion. For PGP9.5 ir fibers (circular muscle), nNOS ir neurons (myenteric plexus) and fibers (circular muscle), VIP ir fibers (circular muscle), substance P ir fibers (circular muscle), TH ir (myenteric plexus), and CD45 and CD206 ir cell bodies (myenteric plexus and circular muscle), two non-adjacent sections were analyzed per participant. Approximately, 20-23 images were randomly collected per patient at $40 \times$ magnification. These were then manually counted to identify positively staining nerve fibers and cell bodies. For nerve fibers, we quantified the number of distinct fluorescent structures with a fiber-like morphology, that is, a connected line of immunofluorescent pixels. We saw no evidence that the shape of the fiber paths are different between diseased and normal tissue and the counts provided include fibers that are broken up more than once in tissues from both groups. Each field was $0.0367 \mathrm{~mm}^{2}$ in size. For quantitative assessment of ICC bodies (circular muscle), 2-3 non-adjacent sections were analyzed per patient. ICC cell bodies were counted from 38 to 40 fields per patient at 40x magnification. An ICC body was defined as a Kit-positive structure with a DAPI-positive nucleus within the structure. Mast cells were excluded by their larger, more circular appearance and brighter fluorescence. The number of images needed for all markers was determined from previous data from quantification from gastric body. ${ }^{1}$

\section{4 | Gastric emptying}

Gastric emptying study was scintigraphy-based using a low-fat egg white meal with imaging at $0,1,2$, and 4 hours after meal ingestion using the standardized protocol to estimate percent gastric retention. This protocol ensures standardized information about delayed gastric emptying across all participating sites. ${ }^{17}$

\subsection{Statistical analysis}

Quantitative data for c-Kit, PGP, nNOS, VIP, substance P, TH, CD45ir, and CD206-ir cell bodies are represented as mean \pm SEM. Statistical significance was determined using the two sided-non-parametric Mann-Whitney test. Simple Pearson's correlation analysis assuming non-parametric distribution was done to relate the histological markers (as measured) with each other and with symptom severity

\section{Key points}

- Macrophages play a critical role in development of delayed gastric emptying in animal models. Their role in human gastroparesis is unclear.

- There is a significant loss of CD206 positive anti-inflammatory macrophages in gastric antrum of patients with diabetic and idiopathic gastroparesis and this correlates with the ICC loss, the key cellular abnormality in gastroparesis.

- Interactions between innate immune cells and other cell types that regulate gastrointestinal motility are important in pathophysiology of gastroparesis and should be further studied.

(overall Gastroparesis Cardinal Symptom Index, GCSI). Spearman $r$ values were reported. A $P<.05$ was considered statistically significant. Exact $P$-values were used and these were not corrected for multiple comparisons. All statistical analyses were carried out using GraphPad 4 software (GraphPad software Inc., La Jolla, CA, USA).

\section{3 | RESULTS}

\section{1 | Demographic profile}

Table 1 lists the demographic profile of diabetic and idiopathic gastroparesis patients. Three of the five controls were females and the median age was 51 years (range 39-65 years). The BMI was higher in diabetic gastroparesis as compared to the idiopathic gastroparesis patients. Remaining demographic characteristics, gastric emptying, and symptom severity scores (average GCSI and sub-scores of nausea, fullness, and bloating) were similar in the two groups.

\section{2 | Gross morphology and assessment of fibrosis}

The H\&E staining showed normal histology of gastric antrum in all samples and trichrome staining showed no evidence of fibrosis in the gastroparesis biopsies.

\section{3 | Interstitial cells of Cajal}

Both diabetic and idiopathic gastroparesis patients showed significant loss of ICC. Diabetic and idiopathic gastroparesis patients had a $62 \%$ and $58 \%$ drop in ICC counts as compared to the healthy controls, respectively (Mean [SEM] for diabetic gastroparesis: 2.28 [0.16]; idiopathic gastroparesis 2.53 [0.47]; controls 6.05 [0.62], P-ANOVA=.004) (Figure 1). No difference was noted between diabetic and idiopathic gastroparesis (Table 2). The loss of ICC was uniform throughout the circular muscle.

\subsection{Enteric nervous system markers}

The overall ir for enteric nerves (PGP9.5) was unchanged (Mean [SEM] for diabetic gastroparesis: 33.64 [3.45]; idiopathic 


\begin{tabular}{|c|c|c|}
\hline & $\begin{array}{l}\text { Diabetic gastroparesis } \\
(n=11)\end{array}$ & $\begin{array}{l}\text { Idiopathic gastroparesis } \\
(n=6)\end{array}$ \\
\hline Age (median, range) & $36,22-56$ years & $34,20-60$ years \\
\hline Sex (n, females) & 8 & 5 \\
\hline BMI (mean \pm SEM) & $26.3 \pm 1.4$ & $20.5 \pm 1.6^{*}$ \\
\hline \multicolumn{3}{|l|}{ Diabetes } \\
\hline Type & Type I-7, Type 2-4 & \\
\hline Duration (mean \pm SEM) & $16.8 \pm 3.8$ years & - \\
\hline $\begin{array}{l}\text { Gastric emptying } \\
\text { (\% Retention at } 4 \text { hrs) } \\
\text { (Mean } \pm \text { SEM) }\end{array}$ & $32.4 \pm 6.4 \%$ & $44.0 \pm 11.9 \%$ \\
\hline GCSI, overall & $3.7 \pm 0.3$ & $3.0 \pm 0.3$ \\
\hline Nausea & $3.9 \pm 0.3$ & $2.7 \pm 0.5$ \\
\hline Fullness & $3.8 \pm 0.3$ & $4.0 \pm 0.3$ \\
\hline Bloating & $3.3 \pm 0.5$ & $2.4 \pm 0.9$ \\
\hline
\end{tabular}

TABLE 1 Demographic characteristics, clinical symptoms, and gastric emptying of patients with diabetic and idiopathic gastroparesis

GCSI, Gastroparesis Cardinal Symptom Index. ${ }^{*} P<.05$.
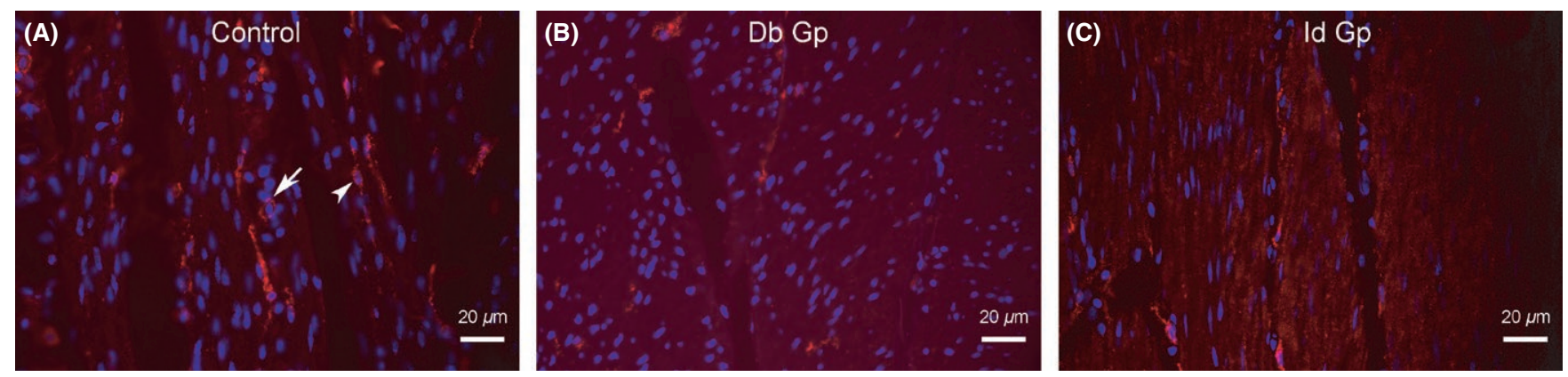

FIGURE 1 c-Kit immunoreactivity (circular muscle) in control (A), diabetic gastroparesis, Db Gp (B) and idiopathic gastroparesis, Id Gp (C) showing significant ICC loss in both diabetic and idiopathic gastroparesis. Arrowhead represents an ICC and arrow represents a mast cell in the field. ICC, interstitial cells of Cajal

gastroparesis 41.26 [6.40]; controls 46.80 [6.04], P-ANOVA=.13) (Figure S1). Excitatory nerve ir (substance $\mathrm{P}$ ir) was unchanged (diabetic gastroparesis: 26.13 [2.41]; idiopathic gastroparesis 29.48 [3.87]; controls 21.67 [1.38], P-ANOVA=.3). Inhibitory nerve ir was unchanged for nNOS ir (diabetic gastroparesis: 27.15 [2.95]; idiopathic gastroparesis: 35.43 [4.75]; controls 26.57 [3.90]) and VIP ir (diabetic gastroparesis: 20.65 [2.19]; idiopathic gastroparesis: 26.32 [2.83]; controls 22.37 [3.89]). The nNOS ir neurons in myenteric plexus was unchanged (diabetic gastroparesis: 1.85 [0.12]; idiopathic gastroparesis: 2.00 [0.34]; controls 2.07 [0.30]). Extrinsic sympathetic nerves $(\mathrm{TH})$ were unchanged in both diabetic and idiopathic gastroparesis as compared to healthy controls (diabetic gastroparesis: 32.50 [4.01]; idiopathic gastroparesis: 41.57 [4.69]; controls 38.32 [4.67]).

\section{5 | Immune cells and CD206 macrophages}

The overall immune cell population was quantified with CD45 ir and was not different in diabetic and idiopathic gastroparesis when compared with healthy controls in circular muscle (Mean
[SEM] for diabetic gastroparesis: 13.82 [1.09]; idiopathic gastroparesis 11.38 [0.54]; controls 19.25 [4.05], $P=.07$ ) and myenteric plexus (Mean [SEM] for diabetic gastroparesis: 14.72 [0.61]; idiopathic gastroparesis 18.34 [2.24]; controls 22.90 [3.15], $P=.09$ ) (Figure S2).

CD206 ir (M2 or anti-inflammatory) macrophages were markedly decreased in both diabetic and idiopathic gastroparesis. In circular muscle, there was a $41 \%$ ir decrease in diabetic and $37 \%$ ir decrease in idiopathic gastroparesis (Mean [SEM] for diabetic gastroparesis: 3.87 [0.32]; idiopathic gastroparesis 4.16 [0.52]; controls 6.59 [1.09], $P=.04$ ). In myenteric plexus, there was a $49 \%$ ir decrease in diabetic gastroparesis and $52 \%$ decrease in myenteric plexus ir (Mean [SEM] for diabetic gastroparesis: 3.83 [0.27]; idiopathic gastroparesis 3.59 [0.68]; controls 7.46 [0.51], $P=.004$ ) (Figure 2).

\subsection{Correlation between CD206 macrophages and ICC}

There was a positive correlation between the CD206 ir cells and ICC $(r=.55, P=.008, \mathrm{n}=22)$ (Figure 3 ). 
TABLE 2 Quantitative immunolabeling data for patients with diabetic gastroparesis, idiopathic gastroparesis, and controls. A HPF represents $0.0367 \mathrm{~mm}^{2}$

\begin{tabular}{|c|c|c|c|c|}
\hline Cellular marker & $\begin{array}{l}\text { Diabetic gastroparesis } \\
(\mathrm{n}=11, \text { mean/HPF } \pm S E M)\end{array}$ & $\begin{array}{l}\text { Idiopathic gastroparesis } \\
\text { ( } n=6, \text { mean/HPF } \pm S E M)\end{array}$ & $\begin{array}{l}\text { Controls }(n=5 \text {, mean } / \\
\text { HPF } \pm \text { SEM) }\end{array}$ & $\begin{array}{l}\text { ANOVA } \\
\text { ( } P \text {-value) }\end{array}$ \\
\hline $\begin{array}{l}\text { c-Kit } \\
\text { (Circular Muscle) }\end{array}$ & $2.28 \pm 0.16$ & $2.53 \pm 0.47$ & $6.05 \pm 0.62$ & .004 \\
\hline $\begin{array}{l}\text { CD45 } \\
\text { (Circular Muscle) }\end{array}$ & $13.82 \pm 1.09$ & $11.38 \pm 0.54$ & $19.25 \pm 4.05$ & .07 \\
\hline $\begin{array}{l}\text { CD45 } \\
\text { (Myenteric plexus) }\end{array}$ & $14.72 \pm 0.61$ & $18.34 \pm 2.24$ & $22.90 \pm 3.15$ & .09 \\
\hline $\begin{array}{l}\text { CD206 } \\
\text { (Circular Muscle) }\end{array}$ & $3.87 \pm 0.32$ & $4.16 \pm 0.52$ & $6.59 \pm 1.09$ & .04 \\
\hline $\begin{array}{l}\text { CD206 } \\
\text { (Myenteric plexus) }\end{array}$ & $3.83 \pm 0.27$ & $3.59 \pm 0.68$ & $7.46 \pm 0.51$ & .004 \\
\hline $\begin{array}{l}\text { PGP } \\
\text { (Circular Muscle) }\end{array}$ & $33.64 \pm 3.45$ & $41.26 \pm 6.40$ & $46.80 \pm 6.04$ & .13 \\
\hline $\begin{array}{l}\text { VIP } \\
\text { (Circular Muscle) }\end{array}$ & $20.65 \pm 2.19$ & $26.32 \pm 2.83$ & $22.37 \pm 3.89$ & .33 \\
\hline $\begin{array}{l}\text { n NOS Neurons } \\
\text { (Myenteric plexus) }\end{array}$ & $1.85 \pm 0.12$ & $2.00 \pm 0.34$ & $2.07 \pm 0.30$ & .82 \\
\hline $\begin{array}{l}\text { n NOS } \\
\text { (Circular Muscle) }\end{array}$ & $27.15 \pm 2.95$ & $35.43 \pm 4.75$ & $26.57 \pm 3.90$ & .27 \\
\hline $\begin{array}{l}\text { Tyrosine Hydroxylase } \\
\text { (Myenteric plexus) }\end{array}$ & $32.50 \pm 4.01$ & $41.57 \pm 4.69$ & $38.32 \pm 4.67$ & .30 \\
\hline
\end{tabular}

\section{7 | Correlation of cellular changes with clinical symptoms}

There was no correlation between the ICC counts and average GCSI $(r=.15, P=.6)$. There was no correlation between the circular muscle CD206 ir cells and average GCSI $(r=-.23, P=.4)$. Similarly, there was no correlation between the myenteric plexus CD206 ir cells and average GCSI ( $r=-.26, P=.4$ ) (Figure S3).

\subsection{Correlation of ICC counts with gastric emptying}

There was no correlation between the ICC counts and percent gastric retention at 4 hours in diabetic $(r=.10, P=.7)$ or idiopathic gastroparesis $(r=.17, P=.8)$ (Figure S4).

\section{4 | DISCUSSION}

The pathogenesis of gastroparesis has been obscure but recent experimental studies support an emerging paradigm in which a shift to a pro-inflammatory macrophage phenotype drives loss of ICC and delayed gastric emptying. ${ }^{8}$ This manuscript highlights a number of similarities with the findings in animal models but also some differences. Firstly, this study confirms that the major gastrointestinal cell type associated with the loss of gastric motility in both diabetic and idiopathic gastroparesis is the ICC. This finding has now been reported by several laboratories and appears to involve both the body and antrum of the human stomach. ${ }^{1,18,19}$ In a study of patients with refractory gastroparesis, ICC loss was present in both diabetic and idiopathic gastroparesis but more profound in idiopathic. ${ }^{18}$ Depleted antral ICC correlated with abnormalities on electrogastrogram and poor symptomatic response to gastric electric stimulation. ${ }^{20}$ The ICC loss observed in the gastric antrum (>60\% loss) in this study is more profound than our previous report in the gastric body ( $35 \%-45 \%$ loss). ${ }^{1}$ These data replicate findings from mouse models observing a greater ICC loss in the gastric antrum than the body. ${ }^{21-23}$ Previously, we have demonstrated significant inverse correlation between ICC counts and 4 hours percent gastric retention in gastric body tissue from diabetic gastroparesis patients (50\% diabetic gastroparetics had $<3 \mathrm{ICC} /$ field). ${ }^{24}$ The more profound nature of ICC loss in gastric antrum (10/11 diabetic gastroparetics had <3 ICC/field) may explain lack of correlation with gastric emptying because beyond a critical loss of ICC, the association with gastric physiology is potentially lost.

The original finding of enteric nerves being preserved in the gastric body in diabetic and idiopathic gastroparesis patients enrolled in the GpCRC appears to extend to the gastric antrum as well. ${ }^{1}$ Immunoreactivity for PGP9.5, a general marker for enteric nerves and neurons was found to be unchanged in gastroparesis. Similarly, immunoreactivity for excitatory nerves, inhibitory nerves, and extrinsic sympathetic innervation was also unchanged in gastric antrum. We did not find an association between GCSI scores and ICC or CD206 ir numbers highlighting the multifactorial central and peripheral mechanisms that sustain symptom generation once established by the primary defect. 

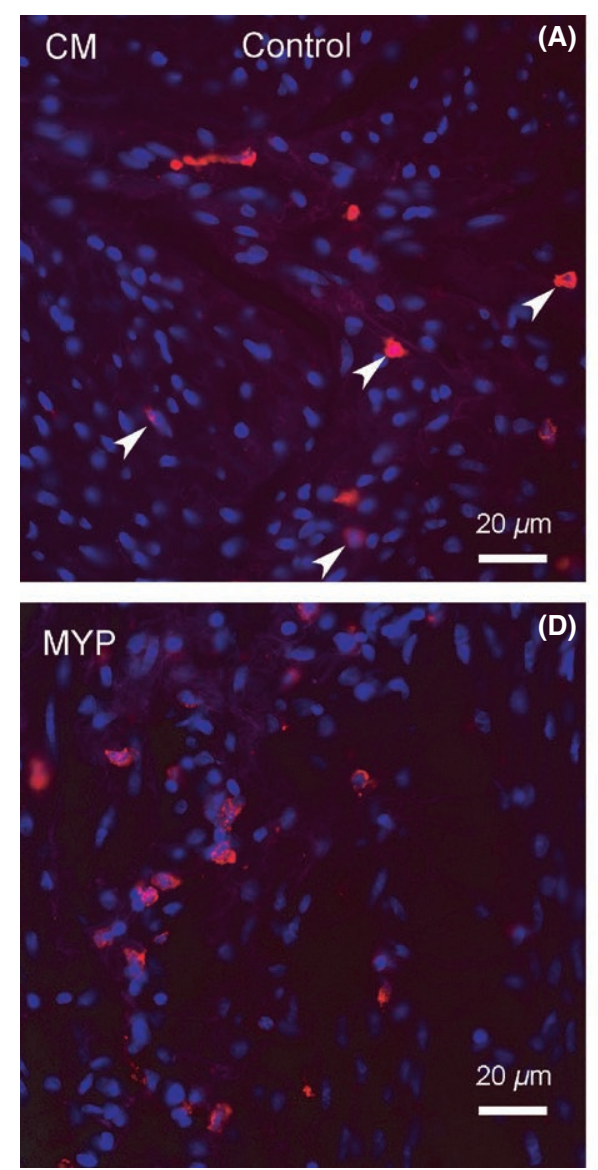
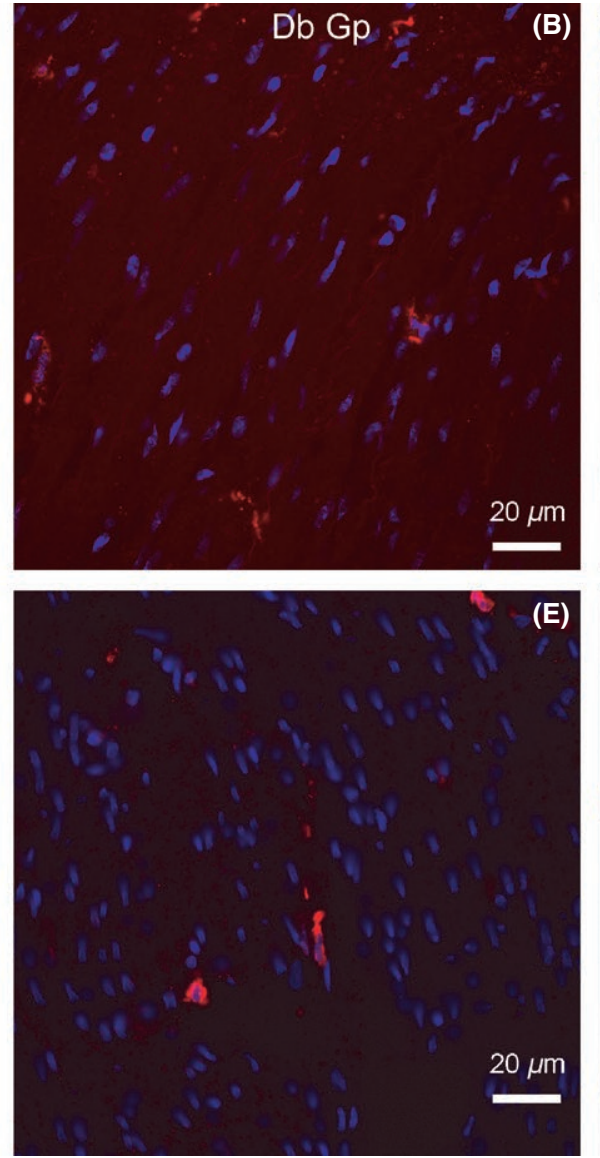

G)
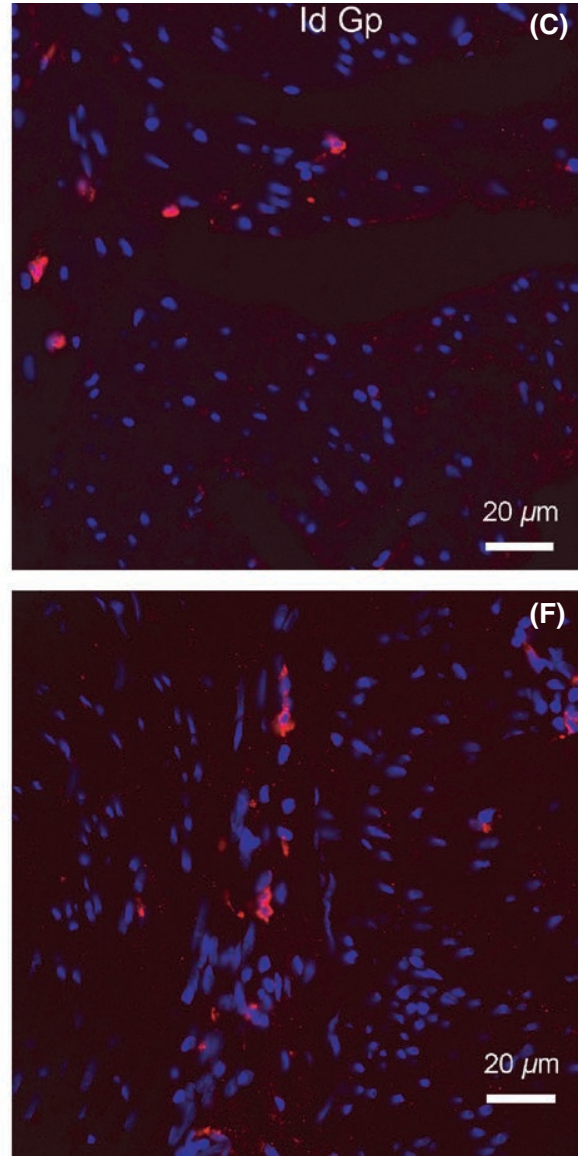

FIGURE 2 CD206 ir (circular muscle) in control (A), diabetic gastroparesis, Db Gp (B), and idiopathic gastroparesis, Id Gp (C); CD206 ir (myenteric plexus) in control (D), diabetic gastroparesis (E), and idiopathic gastroparesis ( $F$ ), both demonstrating loss of M2 (anti-inflammatory) macrophages (represented by arrowheads) in diabetic and idiopathic gastroparesis

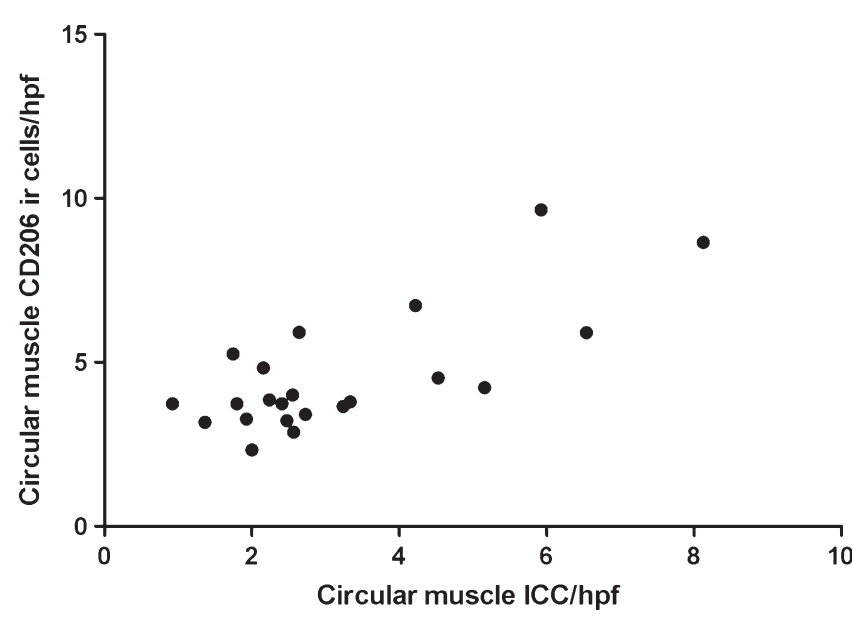

FIGURE 3 Correlation of ICC (circular muscle) and CD206 ir cells (circular muscle) showing significant correlation between ICC loss and loss of anti-inflammatory macrophages. ICC, interstitial cells of Cajal

The involvement of macrophages in the development of delayed gastric emptying was initially described in NOD mice. At the onset of diabetes, anti-inflammatory CD206-positive M2 macrophages populate the muscle wall of the stomach of NOD mice, accounting for nearly $80 \%$ of all macrophages. ${ }^{6}$ However, mice that go on to develop delayed gastric emptying lost their CD206-positive M2 macrophages and expressed M1 macrophages. In contrast to the mouse, the human stomach is populated by a mixture of both CD206-positive and -negative macrophages and rather than absolute loss of a type, the relative number appears to be more important. Nevertheless, our findings are similar in showing a disproportionate loss of CD206 macrophages in patients with gastroparesis. In the antrum, there was a $40 \%-45 \%$ percent loss of CD206 ir cells in circular muscle and $>50 \%$ loss in the myenteric plexus. This is in contrast to our previous study on gastric body where we did not see an absolute loss of CD206 ir macrophages and suggests a more severe defect in the antrum compared to the body. However, as in this study on the antrum, there was a negative correlation between CD206 macrophage counts and ICC numbers.

Contrary to the previous reports of an immune infiltrate in gastroparesis, in this study we did not find evidence for a classical inflammatory cell infiltrate as demonstrated by the normal numbers of CD45 ir cells in this study. The immune dysfunction in gastroparesis therefore appears to be a macrophage-specific process, characterized by a relative or absolute loss of CD206 ir, anti-inflammatory cells. It has been more difficult to examine the changes in the pro-inflammatory M1 macrophage phenotype in humans. As compared to mouse macrophages, there is a paucity of markers for macrophage populations in 
humans. ${ }^{25}$ In mice, resident mucosal and lamina propria macrophages are characterized by the expression of F4/80, CD64, major histocompatibility complex II (MHCII), CD11c, and CX3CR $1 .{ }^{26}$ Classically activated macrophages (M1) can be characterized by high levels of pro-inflammatory cytokines such as interleukin 6 (IL6), inducible nitric oxide synthase (iNOS, NOS2), IL1 $\beta$, and tumor necrosis factor- $\alpha$ $(\mathrm{TNF} \alpha)^{2}{ }^{26,27}$ Alternatively, activated macrophages (M2) have lower levels of C-C chemokine receptor type 2 (CCR2) and CD62L and have an anti-inflammatory signature with increased levels of interleukin 10 (IL10), heme oxygenase-1 (HO1), and CD20. Most of these markers are either not present in human gastrointestinal macrophages or have not been studied. CD206 is a well-studied marker of anti-inflammatory M2-like macrophages and is also expressed in human macrophages but arginase-1 and Ym1 are examples of other proteins that are expressed in mouse but not human M2 macrophages. ${ }^{28}$ There are currently no well-defined markers for human pro inflammatory M1-like or overall macrophages in the gastrointestinal tract. For example, iNOS is robustly expressed in mouse macrophages in inflammation but is epigenetically repressed in human macrophages. ${ }^{29}$ Further studies are therefore necessary to identify and validate novel biomarkers for these cell types in human gastric muscularis propria and to count them either by a single or by a combination of antigenic signatures. Our control tissues are derived from obese subjects, however, previously we have found no changes in kit, PGP9.5, and CD45 ir from gastric body tissues of obese and non-obese subjects making it unlikely that obesity has significant impact on gastric ENS and immune cell markers. ${ }^{1}$

Taken together with the results of experimental studies in mice, the finding that CD206-positive macrophages are decreased in gastroparesis in the antrum suggests that targeting macrophage polarization represents an attractive therapeutic strategy. In NOD mice, up-regulating $\mathrm{HO} 1$ in gastric muscularis CD206 macrophages reverses delayed gastric emptying. ${ }^{30}$ Carbon monoxide, the product of $\mathrm{HO} 1 \mathrm{ac}-$ tivity, has the same effect. ${ }^{31}$ IL10 also increases $\mathrm{HO} 1$ expression in the gastric body of diabetic NOD mice and recovers delayed gastric emptying, electrical slow wave abnormalities, and ICC networks. ${ }^{32}$ This is consistent with the known effects of IL10 in suppressing proinflammatory macrophages and increasing anti-inflammatory macrophages. ${ }^{33}$ IL10 is known to be safe for use in humans. ${ }^{34}$ The recent demonstration that macrophages are necessary for development of delayed gastric emptying in diabetic mice ${ }^{7}$ also suggests that neutralizing the pro-inflammatory cytokines generated by conventionally activated, M1-like macrophages may also serve as a treatment opportunity.

In summary, our findings show that the major gastrointestinal cellular defect in the antrum of patients with diabetic and idiopathic gastroparesis is loss of ICC. Secondly, there is a profound loss of antiinflammatory macrophages in the antrum of both diabetic and idiopathic gastroparesis patients. Further, there is a correlation between ICC and CD206 ir macrophage numbers suggesting that ICC loss may be the result of loss of the anti-inflammatory macrophage subtype. Finally, there is no change in the density of the nerves in the gastric antrum in either diabetic or idiopathic gastroparesis. Overall, these findings provide pathophysiological insights for human gastroparesis being driven by interactions between the innate immune system and ICC and provide a potential rationale for targeting macrophages and the associated inflammatory milieu for the treatment of gastroparesis.

\section{CONFLICTS OF INTEREST}

No competing interests declared.

\section{AUTHOR CONTRIBUTIONS}

MG: study concept and design, acquisition of data, analysis and interpretation of data, drafting of the manuscript, critical revision of the manuscript, statistical analysis, study supervision; CEB: acquisition of data, analysis and interpretation of data, critical revision of the manuscript, statistical analysis; PJP: study concept and design, critical revision of the manuscript; HPP: study concept and design, critical revision of the manuscript; SJG: acquisition of data, critical revision of the manuscript; JT: study concept and design, critical revision of the manuscript; KLK: study concept and design, critical revision of the manuscript; RWM: study concept and design, critical revision of the manuscript; IS: study concept and design, critical revision of the manuscript; WLH: critical revision of the manuscript; LN: critical revision of the manuscript; TLA: critical revision of the manuscript; WJS: critical revision of the manuscript; MLK: material support, critical revision of the manuscript; TAK: material support, critical revision of the manuscript; TJM: material support, critical revision of the manuscript; $\mathrm{FAH}$ : study concept and design, critical revision of the manuscript; GF: study concept and design, acquisition of data, analysis and interpretation of data, drafting of the manuscript, critical revision of the manuscript, study supervision.

\section{REFERENCES}

1. Grover M, Farrugia G, Lurken MS, et al. Cellular changes in diabetic and idiopathic gastroparesis. Gastroenterology. 2011;140:1575-1585 e8.

2. Faussone-Pellegrini MS, Grover M, Pasricha PJ, et al. Ultrastructural differences between diabetic and idiopathic gastroparesis. J Cell Mol Med. 2012;16:1573-1581.

3. Battaglia E, Bassotti G, Bellone G, et al. Loss of interstitial cells of Cajal network in severe idiopathic gastroparesis. World J Gastroenterol. 2006;12:6172-6177.

4. Pasricha PJ, Pehlivanov ND, Gomez G, Vittal H, Lurken MS, Farrugia G. Changes in the gastric enteric nervous system and muscle: a case report on two patients with diabetic gastroparesis. BMC Gastroenterol. 2008;8:21.

5. Iwasaki H, Kajimura M, Osawa S, et al. A deficiency of gastric interstitial cells of Cajal accompanied by decreased expression of neuronal nitric oxide synthase and substance $P$ in patients with type 2 diabetes mellitus. J Gastroenterol. 2006;41:1076-1087.

6. Choi KM, Kashyap PC, Dutta N, et al. CD206-positive M2 macrophages that express heme oxygenase-1 protect against diabetic gastroparesis in mice. Gastroenterology. 2010;138:2399-2409, 409 e1.

7. Cipriani G, Gibbons SJ, Verhulst PJ, et al. Diabetic Csf1op/op mice lacking macrophages are protected against the development of delayed gastric emptying. Cell Mol Gastroenterol Hepatol. 2016;2:40-47. 
8. Neshatian L, Gibbons SJ, Farrugia G. Macrophages in diabetic gastroparesis-the missing link? Neurogastroenterol Motil. 2015;27:7-18.

9. Bernard CE, Gibbons SJ, Mann IS, et al. Association of low numbers of CD206-positive cells with loss of ICC in the gastric body of patients with diabetic gastroparesis. Neurogastroenterol Motil. 2014;26:1275-1284.

10. Thumshirn M, Bruninga K, Camilleri M. Simplifying the evaluation of postprandial antral motor function in patients with suspected gastroparesis. Am J Gastroenterol. 1997;92:1496-1500.

11. Kawagishi T, Nishizawa $\mathrm{Y}$, Okuno $\mathrm{Y}$, et al. Antroduodenal motility and transpyloric fluid movement in patients with diabetes studied using duplex sonography. Gastroenterology. 1994;107:403-409.

12. Fraser RJ, Horowitz M, Maddox AF, Dent J. Postprandial antropyloroduodenal motility and gastric emptying in gastroparesis-effects of cisapride. Gut. 1994;35:172-178.

13. Ordog T, Ward SM, Sanders KM. Interstitial cells of Cajal generate electrical slow waves in the murine stomach. J Physiol. 1999;518:257-269.

14. Forrest AS, Ordog T, Sanders KM. Neural regulation of slow-wave frequency in the murine gastric antrum. Am J Physiol Gastrointest Liver Physiol. 2006;290:G486-G495.

15. Zhang CM, Huang X, Lu HL, et al. Up-regulation of the Ang II/AT1 receptor may compensate for the loss of gastric antrum ICC via the $\mathrm{PI} 3 \mathrm{k} /$ Akt signaling pathway in STZ-induced diabetic mice. Mol Cell Endocrinol. 2016;426:77-86.

16. Wang XY, Huizinga JD, Diamond J, Liu LW. Loss of intramuscular and submuscular interstitial cells of Cajal and associated enteric nerves is related to decreased gastric emptying in streptozotocin-induced diabetes. Neurogastroenterol Motil. 2009;21:1095-e92.

17. Abell TL, Camilleri M, Donohoe $\mathrm{K}$, et al. Consensus recommendations for gastric emptying scintigraphy: a joint report of the American Neurogastroenterology and Motility Society and the Society of Nuclear Medicine. Am J Gastroenterol. 2008;103:753-763.

18. Harberson J, Thomas RM, Harbison SP, Parkman HP. Gastric neuromuscular pathology in gastroparesis: analysis of full-thickness antral biopsies. Dig Dis Sci. 2010;55:359-370.

19. Othman MO, Davis B, Saroseik I, Torabi A, McCallum RW. EUSguided FNA biopsy of the muscularis propria of the antrum in patients with gastroparesis is feasible and safe. Gastrointest Endosc. 2016;83:327-333.

20. Lin Z, Sarosiek I, Forster J, Damjanov I, Hou Q, McCallum RW. Association of the status of interstitial cells of Cajal and electrogastrogram parameters, gastric emptying and symptoms in patients with gastroparesis. Neurogastroenterol Motil. 2010;22:56-61 e10.

21. Ordog T, Takayama I, Cheung WK, Ward SM, Sanders KM. Remodeling of networks of interstitial cells of Cajal in a murine model of diabetic gastroparesis. Diabetes. 2000;49:1731-1739.

22. Horvath VJ, Vittal H, Lorincz A, et al. Reduced stem cell factor links smooth myopathy and loss of interstitial cells of Cajal in murine diabetic gastroparesis. Gastroenterology. 2006;130:759-770.

23. Long QL, Fang DC, Shi HT, Luo YH. Gastro-electric dysrhythm and lack of gastric interstitial cells of Cajal. World J Gastroenterol. 2004;10:1227-1230.
24. Grover M, Bernard CE, Pasricha PJ, et al. Clinical-histological associations in gastroparesis: results from the Gastroparesis Clinical Research Consortium. Neurogastroenterol Motil. 2012;24:531-539.

25. Cipriani G, Gibbons SJ, Kashyap PC, Farrugia G. Intrinsic gastrointestinal macrophages: their phenotype and role in gastrointestinal motility. Cell Mol Gastroenterol Hepatol. 2016;2:120-130 e1.

26. Bain CC, Scott CL, Uronen-Hansson H, et al. Resident and proinflammatory macrophages in the colon represent alternative context-dependent fates of the same Ly6Chi monocyte precursors. Mucosal Immunol. 2013;6:498-510.

27. Tamoutounour S, Henri S, Lelouard H, et al. CD64 distinguishes macrophages from dendritic cells in the gut and reveals the Th1-inducing role of mesenteric lymph node macrophages during colitis. Eur J Immunol. 2012;42:3150-3166.

28. Raes $G$, Van den Bergh R, De Baetselier P, et al. Arginase-1 and Ym1 are markers for murine, but not human, alternatively activated myeloid cells. J Immunol. 2005;174:6561; author reply -2.

29. Gross TJ, Kremens K, Powers LS, et al. Epigenetic silencing of the human NOS2 gene: rethinking the role of nitric oxide in human macrophage inflammatory responses. J Immunol. 2014;192: 2326-2338.

30. Choi KM, Gibbons SJ, Nguyen TV, et al. Heme oxygenase-1 protects interstitial cells of Cajal from oxidative stress and reverses diabetic gastroparesis. Gastroenterology. 2008;135:2055-2064, 64 e1-2.

31. Kashyap PC, Choi KM, Dutta N, et al. Carbon monoxide reverses diabetic gastroparesis in NOD mice. Am J Physiol Gastrointest Liver Physiol. 2010;298:G1013-G1019.

32. Choi KM, Sha L, Verhulst P-J, et al. Treatment with IL-10 reverses gastroparesis in diabetic NOD/Shiltj mice. Gastroenterology. 2012;142:S-66.

33. Deng B, Wehling-Henricks M, Villalta SA, Wang Y, Tidball JG. IL-10 triggers changes in macrophage phenotype that promote muscle growth and regeneration. J Immunol. 2012;189:3669-3680.

34. Asadullah K, Sterry W, Volk HD. Interleukin-10 therapy-review of a new approach. Pharmacol Rev. 2003;55:241-269.

\section{SUPPORTING INFORMATION}

Additional Supporting Information may be found online in the supporting information tab for this article.

How to cite this article: Grover M, Bernard CE, Pasricha PJ, et al. Gastroparesis Clinical Research Consortium (GpCRC), Diabetic and idiopathic gastroparesis is associated with loss of CD206-positive macrophages in the gastric antrum. Neurogastroenterol Motil. 2017;29:e13018.

https://doi.org/10.1111/nmo.13018 